\title{
Sobre a formação da Formaçã̃o econômica do Brasil de C. Furtado
}

\author{
TAMÁS SZMRECSÁNYI
}

$\mathrm{P}$ UBLICADO pela primeira vez há 40 anos e reeditado desde então dezenas de vêzes, sem quaisquer modificações, além de traduzido para várias línguas estrangeiras, Formação econômica do Brasil continua sendo até hoje o livro mais conhecido e mais importante de Celso Furtado. Trata-se de um clássico no sentido literal da palavra, de uma obra pioneira e referencial da nossa historiografia econômica. Ao mesmo tempo, todavia, devido a seu caráter extremamente sintético, não é de fácil assimilação para os que carecem de adequado preparo econômico e/ou histórico.

Na verdade, o livro em questão possui até alguns mistérios, os quais têm freqüentemente instigado seus leitores e usuários, apesar - ou talvez por causa - dos três avisos que figuram na sua Introdução. Dizem estes que: o trabalho não passa de "um esboço do processo histórico de formação da economia brasileira"; por esse motivo, há uma omissão quase total de referências à "bibliografia histórica brasileira"; os seus últimos capítulos baseiam-se, em parte, num trabalho anterior - o livro A Economia Brasileira, publicado pelo autor em 1954 (1).

De modo geral podemos classificar os historiadores econômicos e seus trabalhos em três categorias intelectuais: a dos economistas com conhecimentos de História, a dos historiadores com conhecimentos de Economia, e a dos demais cientistas sociais com conhecimentos tanto de Economia como de História. Com base na leitura da Formação econômica do Brasil, somos levados a incluir o seu autor na primeira dessas categorias. Mas, ao fazê-lo, logo nos deparamos com dois problemas. Um, que se refere principalmente à história do Brasil mas tem também uma conotação historiográfica mais geral: diz respeito à origem dos conhecimentos históricos de Celso Furtado, tão parcamente indicada pelas poucas fontes nacionais e portuguesas que ele cita no seu texto e/ou nas suas notas de rodapé. O outro problema, correlato ao anterior e aparentemente de mais fácil solução, é de natureza teórica e relaciona-se fundamentalmente ao tratamento econômico dispensado pelo autor a seus dados e informações de caráter histórico. 
Entre os 75 nomes de pessoas que figuram no Índice Onomástico da obra (2), apenas 13 (incluindo o próprio Furtado) são de autores de trabalhos em língua portuguesa. Destes, mais da metade (ou seja, sete) não constituem obras de referência, mas fontes documentais de dados e informações das épocas analisadas. Somando-se aos seis restantes, os nomes de sete autores estrangeiros de trabalhos sobre o Brasil em, outras línguas, temos uma bibliografia de apoio constituída de apenas 12 itens, excluindo um artigo do próprio Celso Furtado.

Trata-se, evidentemente, de uma base bibliográfica muito precária para uma obra do alcance e da qualidade da Formação econômica do Brasil. Além dos autores e dos trabalhos ali citados, deve ter havido muitos outros tratando de temas brasileiros, que, embora não-mencionados, foram consultados, lidos e utilizados na sua elaboração. Esta suposição, intuída por Francisco de Oliveira (3), é reforçada pelas coincidências constatáveis entre algumas assertivas e opiniões de Furtado e as de outros autores por ele não-citados, mas cujos trabalhos quase certamente eram do seu conhecimento na época em que seu livro foi elaborado.

Com vistas a procurar suprir tais lacunas, pode-se lançar mão das obras anteriores do próprio autor, procurando identificar por intermédio delas as fontes de dados e de informações que deixaram de ser mencionadas, bem como a bibliografia por ele realmente utilizada. Adotando este procedimento, levantei e analisei não apenas os trabalhos publicados por Celso Furtado antes da Formação econômica do Brasil, mas também a sua tese de doutorado, até hoje inédita, defendida em 1948 na Universidade de Paris (4).

Por meio deste último trabalho, julgo ter encontrado e identificado algumas das referências bibliográficas e documentais não-declaradas pelo autor em seu trabalho posterior, mas que, muito provavelmente, foram levadas em conta por ele durante sua elaboração. De fato, a tese de Furtado, da qual possuo uma fotocópia enviada por um amigo, traz logo no seu início uma bibliographie choisie de três folhas não-numeradas, agrupando autores e obras em língua portuguesa e em outros idiomas, seguida por um breve primeiro capítulo sobre as fontes utilizadas (5).

Nessas primeiras páginas do seu trabalho de doutorado figuram numerosas obras e diversos autores que não aparecem na Formação econômica do Brasil, mas, com grande probabilidade, devem ter integrado aquela bibliografia histórica brasileira que Celso Furtado, em sua Intro$d u c ̧ \tilde{a} o$ a essa obra, informa ter omitido do seu esboço. 
Entre os trabalhos incluídos na bibliografia selecionada da tese, cumpre mencionar os livros de Capistrano de Abreu, Capitulos da história colonial; Caio Prado Jr., História econômica do Brasile Formação do Brasil contemporâneo; e de Nelson Werneck Sodré, Formação da sociedade brasileira - para mencionarmos apenas os autores nacionais mais especializados em nossa história econômica e social. Entre os trabalhos de autores estrangeiros ali referidos, cabe citar o estudo de Louis Couty, L'esclavage au Brésil, ao qual se podem acrescentar, já no capítulo sobre as fontes utilizadas, referências às obras de J.F. Normano, Brazil, a study of economic types; René Courtin, Les problèmes de la civilisation économique au Brésil; e de Hermann Watz, Das Hollaendische Kolonialveich in Brasilien.

Nenhum deles chegou a ser citado na Formação econômica do Brasil. $\mathrm{Na}$ verdade, a única obra precursora que Celso Furtado chega a mencionar com destaque tanto neste livro como em sua tese de doutorado é a História econômica do Brasil, de Roberto Simonsen, publicada pela primeira vez em 1944 e reeditada em 1957. Embora esse procedimento seletivo quanto às fontes possa ser justificado pelas diferenças de natureza e de conteúdo dos dois trabalhos (um de análise em profundidade de parte do período colonial, elaborado para a obtenção do doutorado, e outro de síntese, relativo a um tempo mais amplo e destinado a um público maior e mais geral), ou por quaisquer outros motivos (6), não há dúvida de que as lacunas bibliográficas do segundo acabam dificultando a sua interpretação e avaliação, particularmente no que se refere ao posicionamento historiográfico do autor.

Trata-se de um problema que também está presente em outros trabalhos históricos de Furtado, posteriores à sua tese e anteriores à Formação. Trabalhos que incluem não apenas o livro já referido no início desta comunicação, mas também dois artigos (7) e um fascículo publicado pelo Ministério da Educação (8).

Antes de passar a eles, convém fazer uma apreciação mais geral do trabalho de doutoramento do autor.

Diversamente da Formação econômica do Brasil, esse trabalho foi desenvolvido no contexto mais genérico de uma ciência social voltada tanto para a História quanto para a Economia. Celso Furtado era então apenas um estudante de pós-graduação, bacharel em Direito e funcionário do Serviço Público brasileiro, ainda à procura de novos caminhos teóricos e práticos. Só mais tarde é que ele optaria por uma inserção mais especializada nas ciências econômicas. 
Com efeito, no primeiro capítulo de sua tese, ele dizia estar procurando: discutir as hipóteses de trabalho do ensaísta português António Sérgio sobre a evolução da burguesia comercial e marítima daquele país (9); analisar a formação colonial brasileira à luz da documentação disponível e das idéias pioneiras de Gilberto Freire (Casa Grande e Senzala) e de Caio Prado Jr. (Formação do Brasil Contemporáneo) (10); aplicar no seu estudo de caso a teoria do historiador belga Henri Pirenne sobre "a correlação dos períodos da história social do capitalismo com a formação de novas elites dirigentes" (11).

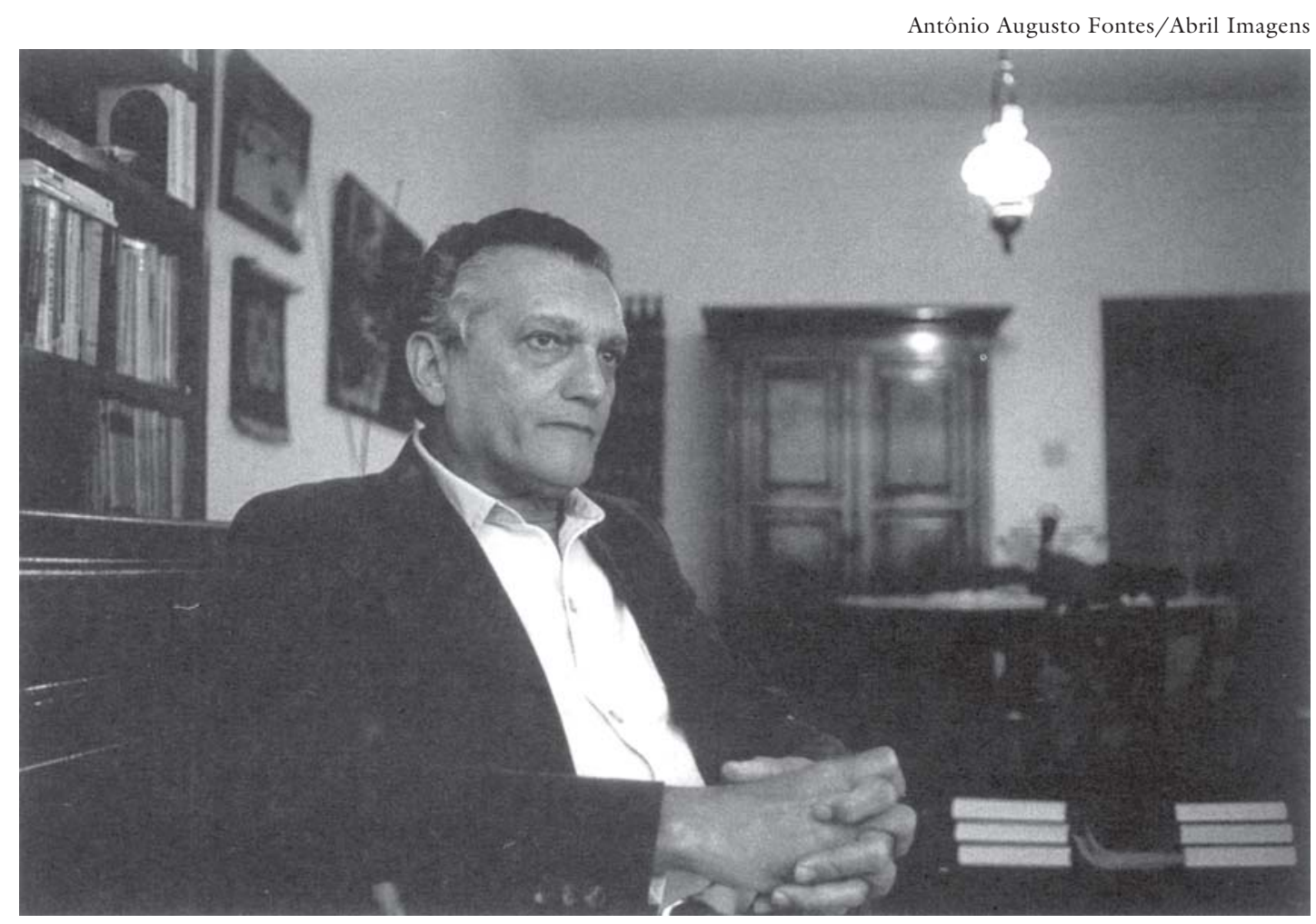

Celso Furtado

Tais objetivos correspondiam às três partes de sua tese, intituladas: "Antecedentes portugueses da colonização do Brasil" (capítulos II e III, fls. 12-57); "A formação da colônia" (com mais quatro capítulos, fls. 58155); e Os atavismos coloniais do Brasil moderno" (quatro capítulos finais, fls. 156-187).

Os temas mencionados foram mantidos apenas em parte nas obras subseqüentes de Celso Furtado, enquanto as preocupações mais gerais, que inicialmente orientaram o seu estudo, acabaram sendo descartadas por ele já nos primeiros trabalhos que publicou após a sua volta da Fran- 
ça e seu ingresso nos quadros da CEPAL. Tais preocupações foram substituídas por uma visão do mundo essencialmente econômica, para não dizer economicista e tecnocrática, tornando mais difícil o entendimento de seus trabalhos para os leitores desprovidos de maiores conhecimentos de Economia.

$\mathrm{Na}$ verdade, esses trabalhos já permitem vislumbrar, em todo seu vigor, o surgimento nele do economista profissional, do técnico internacional, do homem público e do político, funções que foi assumindo sucessivamente depois de seu doutorado. Nesse sentido, o ingresso na CEPAL parece ter significado, para ele, uma segunda pós-graduação na qual teve de aprender e reaprender muito rapidamente para poder vir a diagnosticar e a ensinar.

Dentro dessa perspectiva, o artigo Características gerais da economia brasileira, publicado em 1950 apresenta, de forma condensada, alguns dos pressupostos teóricos e várias hipóteses de trabalho que norteariam a argumentação de Furtado em Formação econômica do Brasil. Na sua primeira parte já encontramos referencias à sucessão de ciclos de produtos no desenvolvimento da economia brasileira, ao mecanismo cambial de socialização das perdas do setor agroexportador, às tendências para a concentração da renda, aos desequilíbrios estruturais ocasionados pela piora na relação de trocas e à lentidão da formação no país, tanto do mercado interno quanto "de um autêntico espírito de empresa, condição básica do desenvolvimento de uma economia capitalista” (12). A Segunda parte desse artigo trata do início da industrialização do Brasil (13); a terceira examina os problemas decorrentes da crise de 1929 e da depressão dos anos 30 (14); a quarta chama a atenção para as novas perspectivas da economia brasileira a partir de sua integração nacional no pósguerra (15).

Essas análises empíricas foram retomadas, ampliadas e aprofundadas no livro de 1954, que marcou também a volta de Celso Furtado à temática de sua tese de doutorado, abordada de forma explicita nas páginas finais do segundo capítulo daquela obra (16), intitulada "A unidade colonial exportadora escravocrata" e, indiretamente no capítulo primeiro, sobre "As categorias fundamentais do processo histórico de crescimento econômico" (17). Os capítulos mais importantes desse livro, porém, no que se refere à retomada de sua temática na Formação econômica do Brasil, são o terceiro, relativo à evolução da economia cafeeira, e o quarto, a respeito de sua crise e do desenvolvimento industrial subseqüente a partir dos anos 30 . 
Como bem observou Francisco Iglésias (18), A economia brasileira nunca foi reeditado pelo fato de suas várias partes terem sido retomadas, às vezes literalmente, em trabalhos posteriores de Furtado. Um deles foi o fascículo Uma economia dependente, de 1956, no qual já encontramos um embrião da Formação econômica do Brasil (19). Alguns subtítulos de seus três capítulos, além de refletirem os da obra anterior, ressurgiriam na de 1959.

Esta, segundo se sabe, foi elaborada em sua versão definitiva durante o estágio de Celso Furtado na Universidade de Cambridge, na Inglaterra, em 1957-58. Ali ele pôde ter acesso a boas bibliotecas, ler muito, entrar em contato com renomados economistas, amigos e discípulos de Keynes, e, principalmente, amadurecer as suas próprias idéias, dando origem ao "principal livro que já publicou e [a] uma das obras mais notáveis da bibliografia [histórica] brasileira" (20).

Vários de seus capítulos eram inteiramente novos, não constando de qualquer um dos seus trabalhos anteriores (21). Outros foram inteiramente reescritos e bastante aprofundados a partir deles (22). E todos permanecem modelares até hoje, não obstante as restrições que se possa fazer a um ou outro aspecto de sua argumentação.

O tratamento econômico dispensado por Furtado aos dados e às informações de cunho histórico é de índole cepalina e keynesiana. Podemos encontrar a conceituação dos termos nele utilizados num conjunto de 10 conferências proferidas pelo Autor no segundo semestre de 1957, e reunidas num fascículo intitulado Perspectiva da economia brasileira, publicado no ano seguinte pelo Serviço de Documentação do DASP (Departamento Administrativo do Serviço Público). Nessas conferências não há notas de rodapé nem citações bibliográficas. As proposições ali apresentadas estão muito distantes das que constavam da tese de doutoramento defendida por Celso Furtado dez anos antes.

O estudante de Ciências Sociais que ele fora naquele tempo cedeu lugar ao profissional especializado em Economia e ao alto funcionário governamental em que se havia transformado nos anos 50. Mas, como também sabemos, essa evolução acabaria não sendo definitiva e irreversível. Devido às contingências políticas do golpe militar de 1964, Celso Furtado deu uma nova guinada em sua carreira, transformando-se novamente, a partir daquela época, num cientista social e num acadêmico.

Embora nunca tenha alterado uma vírgula sequer da Formação econômica do Brasil, Furtado publicou, dez anos mais tarde, a sua Formação 
econômica da América Latina. Ao contrário do anterior, este livro foi por ele devidamente modificado e ampliado, além de complementado por outros trabalhos mais recentes. A comparação destes, e do restante de sua obra, com a Formação econômica do Brasilainda está para ser feita. Só ela poderá nos fornecer um balanço mais completo e mais preciso de sua contribuição efetiva à historiografia econômica do Brasil.

\section{Notas}

1 Celso Furtado, Formação econômica do Brasil, 14 a ed. São Paulo, Nacional, 1976, p. 1-2.

$2 I d .$, ibid., p. 243.

3 Introdução. A navegação venturosa. In: Francisco de Oliveira (org.), Celso Furtado: Economia. São Paulo, 1983, Atica-coleção Grandes Cientistas Sociais n. 33, p. 13.

4 Celso M. Furtado, L'économie coloniale brésilienne (XVI et XVII siècles). Paris, juin 1948. Université de Paris-Faculté de Droit, 187 fls. [datilografadas].

5 Id., ibid., fls. 1-11.

6 Francisco Iglésias chegou a atribuí-lo à "fraqueza” da historiografia brasileira... Cf. Celso Furtado, pensamento e ação. In Francisco Iglésias, História e ideologia. São Paulo, Perspectiva, 1971, p. 200. Minha própria interpretação é de índole política.

7 Celso Furtado, Características gerais da economia brasileira. Rev. Brasileira de Economia, v. 4, n. 1, p. 7-33, mar. 1950; O desenvolvimento econômico (ensaio de interpretação histórico analítica). Economica Brasileira, v. 1, n. 1, p. 3-23, mar. 1955.

8 Id., Uma economia dependente. Rio de Janeiro, Imprensa Nacional, série Cadernos de Cultura, n. 94, 1956. 73 p.

9 Id., L'économie coloniale brésilienne, op. cit., p. 3.

10 Id., ibid., fls. 4-10.

11 Id., ibid., fls. 11.

12 Id., ibid., p. 7-12.

13 Id., ibid., p. 13-23.

14 Id., ibid., p. 23-28. 
15 Id., ibid., p. 28-31.

16 Id., A economia brasileira (contribuição à análise de seu desenvolvimento). Rio de Janeiro, Editora A Noite, 1954, p. 71-79.

17 Id., ibid., p. 19-47. Nesse capítulo há referências ao papel do comércio, que são evocadoras das idéias de Pirenne sobre o mesmo tema.

18 Francisco Iglésias, História e ideologia, op. cit., p. 168.

19 Outro foi o já citado artigo de 1955, O desenvolvimento econômico.

20 Francisco Iglésias, op. cit., p. 188.

21 Esse é o caso dos capítulos: X, sobre a pecuária; XIII a XV, sobre a economia escravista mineira; XVI sobre o Maranhão; XIX e XXV, sobre os níveis de renda do Brasil no século passado.

22 Como os capítulos XXI e XXIV, relativos ao "problema da mão-de-obra".

Tamás Szmrecsányi é professor do Departamento de Política Científica e Tecnológica do Instituto de Geociências da Unicamp (Universidade Estadual de Campinas) e integrante do Conselho Editorial de ESTUDOS AVANÇADOS. E-mail: dpct@ige.unicamp.br.

O texto foi apresentado pelo autor no módulo VIII - "Metodologia da História Econômica", do III Congresso Brasileiro de História Econômica, realizado em Curitiba, agosto/setembro de 1999. 